\title{
Proposta de metodologia de testes para avaliar a percepção visual e a preferência subjetiva de crianças surdas
}

\author{
Tests Methodology to evaluate visual perception and subjective \\ preference in Deaf children
}

Juliana Bueno, André Luiz Alencar de Mendonça e Laura Sánchez García

crianças surdas, língua de sinais, percepção visual, gestalt deaf children, sign language, visual perception, gestalt
O emprego de testes com crianças surdas para avaliar características visuais é o ponto central desta pesquisa. É proposta uma metodologia de teste enfocando aspectos da percepção visual e preferência subjetiva para cor deste público. Tal metodologia tem por objetivo medir quais variáveis visuais influenciam de modo positivo na realização de tarefas em materiais didáticos utilizados para a aprendizagem em contexto ensino bilíngue de surdos. Os testes são descritos em detalhes, a fim de serem replicáveis em outras escolas e foram validados em um estudo de caso que gerou algumas discussões de ordem qualitativa.

The use of tests with deaf children to evaluate visual characteristics is the focus of this research. We're proposing a tests methodology focusing on aspects of visual perception and subjective preference for color of this audience. This methodology aims to measure which visual variables influence positively during the execution of tasks in didactics materials used for learning in bilingual education for the deaf. The tests are described in detail in order to be replicable in others schools and were validated in a case study that generated some discussion of qualitative order.

\section{Introdução}

O contexto atual e a exigência da acessibilidade dos sistemas de informação e do design de artefatos para a inclusão social tornam necessárias investigações que aprofundem o conhecimento específico sobre os surdos de Língua de sinais (LS).

As pesquisas que buscam listar as estratégias cognitivas utilizadas pelos surdos nos ambientes educacionais assumem, até então, características levantadas em pesquisas experimentais advindas da psicologia behaviorista, que raramente tratou o tema com a devida validação ecológica e inserção social que se julga necessária para este tipo de estudo. Também, estas sempre buscaram comparar as capacidades cognitivas deste público em contrapartida a ouvintes. 
Neste trabalho, o viés está unicamente direcionado ao público surdo, mais especificamente crianças surdas em contexto lúdico.

Propõe-se aqui, uma metodologia de testes para investigar a percepção visual e a preferência subjetiva para cores de crianças surdas. E, também, um teste de mensuração de Língua Brasileira de Sinais (Libras) por ser a língua natural dos surdos: sua ferramenta de comunicação, criação de conhecimento e outros aspectos relacionados à linguagem. O objetivo da metodologia é medir quais variáveis visuais influenciam de modo positivo na realização de tarefas em materiais didáticos utilizados para a aprendizagem em contexto ensino bilíngue de surdos. Assim, possibilita-se a construção de conhecimento robusto, que pode auxiliar designers no desenvolvimento de materiais educacionais mais efetivos e que tenham maior aceitação por parte deste público.

Parte-se primeiramente de uma fundamentação teórica acerca do assunto, na qual se procura demonstrar a importância da LS e da comunicação visual para os surdos. Depois disto, são explicadas as variáveis visuais analisadas nos testes e a metodologia proposta. Em seguida, é apresentado um estudo de caso com 15 crianças surdas que validou a metodologia. E por fim, faz-se uma discussão dos principais resultados obtidos com os testes preliminares.

\section{Premissas}

\subsection{LSS}

As LSs são consideradas pela linguística como línguas naturais, com sistemas linguísticos legítimos e não "um problema dos surdos" ou "patologias da linguagem" (QUADros, 2006). Já o atraso na aquisição da linguagem por crianças surdas tem como consequência atrasos emocionais, sociais e cognitivos, considerando-se a linguagem num conceito mais amplo, abrangendo, além da função comunicativa, a função organizadora do pensamento (FERNANDES, 2006).

A LS será adquirida pela criança surda na medida em que ela puder interagir com usuários desta língua. Infelizmente, não são todas as crianças surdas que têm esse privilégio, pois segundo dados de Stumpf (2005, P. 23), cerca de 90\% dos pais de crianças surdas são ouvintes. Os pais também precisam aprender a Língua de sinais, mas os que o fazem ainda são uma parcela não significativa.

Outro aspecto de importância para este estudo diz respeito à suficiência em uma LS. Fala-se na necessidade de aprendizado da LS pelo surdo, mas a mensuração da eficiência deste, não é comumente aferida de forma padronizada e largamente difundida no Brasil. 


\subsection{Os surdos e a comunicação visual}

Grande parte da metodologia proposta para o presente estudo está atrelada à importância do aspecto "visual" em processos de ensino e aprendizagem. Para Fernandes (2006, P.20), a hipótese inicial de leitura para a criança surda deve acontecer pelo "casamento" entre as imagens e os textos. Nos materiais específicos para o letramento da criança surda, independentemente de sua natureza, é importante que sejam oferecidos textos interessantes e ricos em imagens, com apelo visual (FERNANDES, 2006). A mesma autora afirma que a leitura de imagens e a sua relação com o conhecimento prévio da criança permitem o despertar da atenção e do interesse pelas possíveis mensagens que o texto veicula. Capovilla et al. (P.21, 2005) atesta a importância da leitura visual. Segundo suas pesquisas, a leitura pelo surdo é totalmente dependente de mecanismos visuais diretos de reconhecimento e de acesso ao significado.

Mesmo chamando a atenção para a importância do uso da imagem vinculado ao texto, a literatura deixa claro que a escola ainda pouco sabe apropriar-se de recursos visuais para o ensino-aprendizado dos surdos. Sofiato (2005) diz que a imagem tem um importante papel no processo educacional. A autora afirma que o uso e o significado da imagem no contexto educacional dá origem à escrita e que desde muito cedo aprendemos a ler imagens ou mensagens visuais.

Mirzoeff (1999) advoga que existe um impacto inicial à primeira vista em uma imagem que um texto escrito nunca poderá provocar. No contexto das mídias de comunicação visual de apoio ao aprendizado, o autor afirma que o ensino baseado na aplicação de imagens visuais apoiadas em uma tradição estruturalista ou baseada somente em palavras, nega o elemento que torna o imageamento de qualquer tipo diferenciado em relação a textos em geral, que é o imediatismo sensitivo.

Acerca da relação entre a surdez e as habilidades cognitivovisuais, diversos autores apontam para a existência de indicativos de que a experiência com uma Língua de sinais faz com que os surdos possuam características e estratégias específicas, quando analisados determinados aspectos visuais, especialmente naqueles considerados de alto nível como o reconhecimento facial (MCCULLOUGH \& EMMOREY, 1997), transformação, rotação e visualização em representações mentais (EMMOREY, KOSSLYN, BELLUGI, 1993), completude gestáltica (SIPLE ET AL. 1978), construção e transformação de objetos (BELLUGI, POIZNER, KLIMA, 1989), memória relativa a formas apresentadas simultaneamente (TODMAN \& SEEDHOUSE, 1994).

Estudos como o de Parasnis et al. (1996) demonstram que a surdez por si só parece não contribuir para diferenças no desempenho de atividades visuais entre surdos e ouvintes, o que leva à ideia de que o aprendizado de uma LS seja primordial para determinar tais diferenças, dado o caráter intrinsecamente visual-espacial desta língua. 


\subsection{Variáveis gráficas e Gestalt}

Bertin (1983) classificou o uso de elementos visuais na representação de dados e suas relações. O autor enfatiza sete variáveis gráficas ou visuais que são fundamentais em qualquer representação visual: cor, forma, tamanho, posição, orientação, valor e textura. O modo como o ser humano percebe e processa tais variáveis está relacionado aos princípios da Gestalt.

Conforme cita Gomes Filho (2004), os chamados "psicólogos da Gestalt", baseados numa série de experimentos, determinaram que há certas constantes responsáveis pelo modo como agem nossas forças internas no que diz respeito àquilo que vemos. Essas constantes são: Unidade (relacionada com a forma); Segregação (a capacidade de reconhecer as unidades); Unificação (coesão visual como uma função de maior equilíbrio e harmonia); Fechamento (completude); Continuidade (sequência e fluidez); Proximidade (elementos próximos uns dos outros tendem a ser vistos juntos); Similaridade (estímulos semelhantes tendem a se agrupar em unidades) e Pregnância da Forma (formação da imagem, equilíbrio, clareza e harmonia visual).

Assim, no que diz respeito à criação de materiais educacionais, talvez o objetivo mais relevante de se estudar as teorias da Gestalt, especialmente aplicadas a um experimento acerca da percepção visual, é proporcionar ao designer a possibilidade de controlar aquilo que os usuários do produto veem, ao observar determinada composição visual, no exato momento em que a observam.

\section{Passo a passo metodológico}

O diferencial da metodologia proposta está em retirar o contexto experimental e toda a carga de conceitos associados a este. Dando importância à abordagem etnográfica e à necessidade de adotar um caráter lúdico à aplicação dos testes. Para isso, foram elaborados jogos.

O jogo é um processo crucial para se compreender ideias, desenvolver habilidades e participar de papéis sociais, ele ainda, ajuda a construir um contexto de aprendizagem e aumenta a motivação e envolvimento (VIGOTSKY, 1974).

Deve-se ressaltar que todos os procedimentos metodológicos devem obedecer às normas éticas vigentes e, principalmente, garantir aos participantes o anonimato e a não-divulgação de quaisquer aspectos individuais nos resultados obtidos.

\subsection{Testes propostos}

A proposição dos testes (jogos) deu-se basicamente a partir das teorias de Bertin para a escolha das variáveis gráficas a serem avaliadas (cor, forma e tamanho) e das teorias da Gestalt. 


\section{Mensuração de fluência e domínio de Libras}

Objetivo: Realizar a mensuração preliminar do domínio e da fluência do entrevistado em Libras. Esta variável, no escopo desta atividade, foi classificada dentro de 4 classes, a saber:

1. Classe "nenhum domínio", que inclui o indivíduo que não consegue narrar um fato satisfatoriamente usando a língua, não possui nenhuma facilidade e espontaneidade ao utilizá-la e não consegue identificar sinais básicos, em sua maioria;

2. Classe "pouco domínio", que inclui o indivíduo que não consegue narrar um fato satisfatoriamente usando a língua, não possui facilidade ou espontaneidade ao utilizá-la, mas consegue identificar sinais básicos, em sua maioria;

3. Classe "domínio básico, sem fluência", que inclui o indivíduo que consegue narrar um fato satisfatoriamente usando Libras, não possui facilidade ou espontaneidade ao utilizá-la, mas consegue identificar sinais básicos, em sua maioria;

4. Classe "domínio pleno e fluência", que inclui o indivíduo que consegue narrar um fato satisfatoriamente usando Libras, possui facilidade ou espontaneidade ao utilizá-la e consegue identificar sinais básicos, em sua maioria.

Justificativa: o nível de domínio e de fluência em Libras se justifica como variável do experimento pela hipótese de que as pessoas surdas que se comunicam por meio dela (língua de caráter visualespacial) detêm capacidades perceptivas próprias que as diferenciam das demais que não se comunicam. As classes estabelecidas foram baseadas no teste de suficiência da Língua de Sinais Americana (ASL).

Procedimento: o intérprete deve avisar à turma que farão uma brincadeira juntos. Depois disso, escolherá um participante e irá cumprimentá-lo utilizando-se de sinais básicos ("Oi", "Bom dia", "Boa tarde", "Como vai?", "Qual é o seu nome?", "Quantos anos você tem?", "Vamos brincar?"). O ajudante então deve entregar ao primeiro escolhido uma sacola com vários objetos (brinquedos em geral) e lhe pedir que tire um aleatoriamente. Após a escolha, o intérprete deve pedir ao aluno que conte para a turma algo sobre o objeto em 60 segundos, devendo o aluno ser estimulado a continuar, caso pare. $\mathrm{O}$ intérprete deve deixar o aluno à vontade para contar à turma o que desejar sobre o objeto.

Forma de Avaliação: primeiramente o intérprete deve observar o entendimento dos sinais básicos, usando como parâmetro a resposta do entrevistado. Então, o intérprete deve verificar, primeiramente, se a narração é compreensível e faz sentido por si só. Segundo, verificar a qualidade dos sinais usados, bem como a espontaneidade com que estes são usados (parâmetros sugeridos são o excesso de pausas, o 
tempo utilizado e a riqueza narrativa). Terceiro, verificar se o fato narrado possui relação com o objeto utilizado. A avaliação deve ser feita por meio de um formulário individual contendo espaço para o nome da criança, idade, série, notas de 1 a 4 (para serem assinaladas) e observações.

Participantes e duração: para uma maior interação, as crianças participarão do teste todas juntas. Espera-se que a duração por aluno seja no mínimo 2 minutos, no máximo 5. Deve existir no ambiente no mínimo 1 intérprete e 2 ajudantes, um para ajudar com os brinquedos, outro para preencher o formulário. Se possível, aconselha-se que existam mais intérpretes, que possam também fazer a avaliação. A nota final do aluno deve ser a média aritmética da soma de cada uma das avaliações realizadas.

\section{Teste de percepção: Cor, Forma, Tamanho - "Jogo da Memória"}

Objetivo: avaliar qual das variáveis visuais analisadas é percebida “primeiro", no sentido de ser escolhida à primeira vista.

Justificativa: este resultado poderia ser aproveitado, por exemplo, para a aplicação da variável visual mais rapidamente percebida em elementos que merecem maior destaque em materiais de ensino-aprendizagem.

Preparação: as cartelas para o jogo foram especialmente desenvolvidas de maneira a expressarem proporcionalmente, as três variáveis objeto do estudo, em detrimento das demais variáveis visuais.

Procedimento: após separar o grupo em duplas, o intérprete deve explicar à dupla da vez que ela irá jogar o jogo da memória e que deve olhar atentamente para o cartaz $\mathrm{A} 3$ à sua frente (este contem uma das configurações propostas, por exemplo, a Figura 1) durante 10 segundos. Passado este tempo, o participante pode começar a virar as cartas-figuras que estão na mesa à sua frente e que já foram organizadas pelo ajudante na mesma ordem da configuração apresentada no cartaz.

Forma de avaliação: um formulário de avaliação deve ser preenchido e deve conter o nome da criança, configuração utilizada das figuras ( $1 \mathrm{a}$ 4), o nome da figura correspondente à primeira tentativa de abertura das cartas-figuras, nome da figura correspondente à primeira tentativa bem-sucedida de abertura das cartas-figuras e observações.

Participantes e duração: no máximo 2 alunos por vez, com no mínimo 1 intérprete e 2 ajudantes. Os alunos têm até 5 minutos para completar o jogo. 


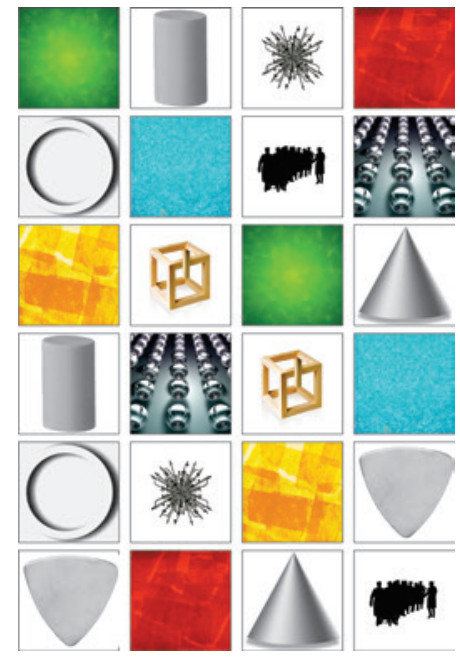

Figura 1 Exemplo de configuração das cartelas para a tarefa "Jogo da Memória".

Particularidades: são usadas 4 diferentes configurações para evitar que uma das crianças se influencie pelo jogo de seu oponente.

Teste de percepção da variável cor: "Jogo dos 7 Erros”

Objetivo: avaliar a eficiência da variável cor para identificação de particularidades em imagens.

Justificativa: os resultados poderão orientar o uso ou o não uso da cor em apresentação de informação visual detalhada.

Procedimento: o intérprete deve escolher alunos em quantidade par e lhes explicar que devem achar os 7 erros entre as duas figuras retiradas de histórias em quadrinho de Maurício de Sousa (Figura 2).
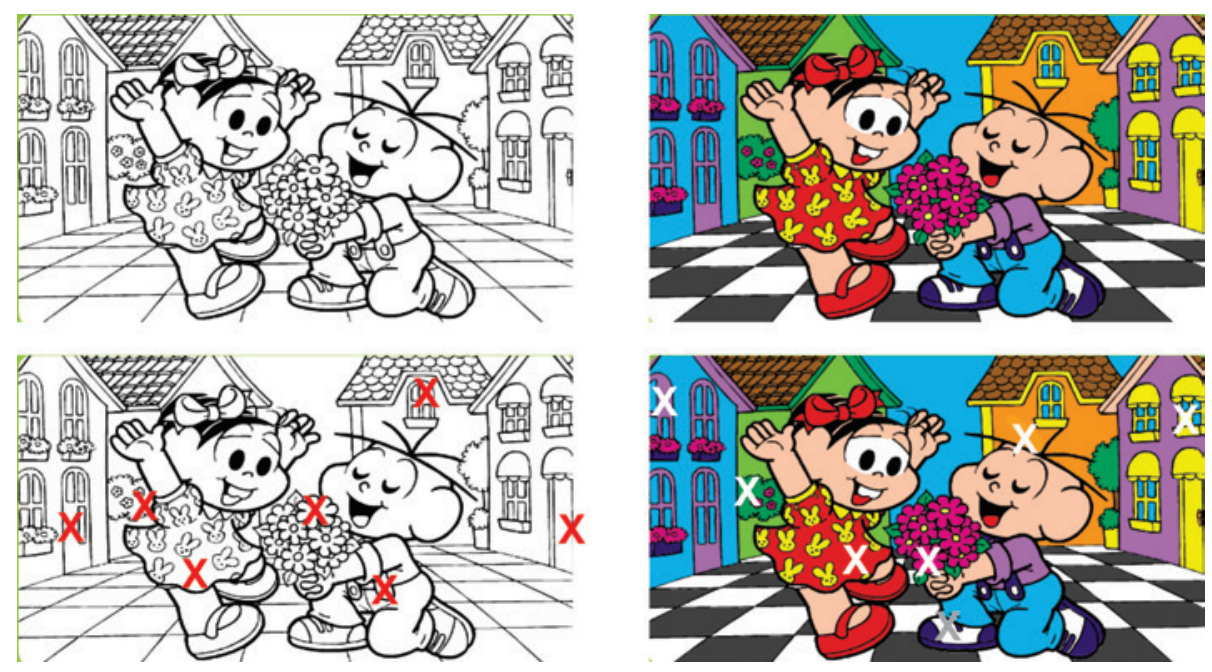

Figura 2 "Jogo dos 7 Erros" em PB e em Cores. 
Forma de Avaliação: o intérprete deve anotar em um formulário apropriado o nome da criança, em quanto tempo foi achado cada erro, em quanto tempo foram achados os 7 erros, anotar caso não tenham sidos achados todos os erros e observações.

Participantes e duração: no mínimo 2 alunos por vez, enquanto um faz o teste em preto e branco, o outro faz em cores. Sendo que ao finalizar um dos testes, o aluno recebe o outro. No mínimo 1 intérprete e 1 ajudante para cada aluno. Os alunos têm até 5 minutos para completar o jogo.

\section{Percepção de completude: "Jogo do Adivinhe a Figura"}

Objetivo: esta atividade se utiliza da componente gestáltica "completude visual" para analisar qual o nível de dificuldade - dado pela quantidade de pontos usada na figura - é considerado suficiente para levar à identificação de uma figura.

Justificativa: os resultados podem ajudar na determinação dos estilos de ilustrações, em termos de complexidade, a serem apresentadas às crianças em materiais educacionais.

Procedimento: o intérprete deve distribuir, para o aluno, a figura considerada mais difícil para visualização primeiramente. Ao entregar a figura, ele deve perguntar ao aluno: "O que você vê aí?". A resposta deve vir em no máximo 10 segundos. Após este período, caso a resposta não seja dada ou não seja satisfatória, o intérprete deve entregar a segunda figura, por ordem de dificuldade, e repetir a pergunta. O procedimento deve ser repetido até que o aluno dê a resposta correta (Figura 3).

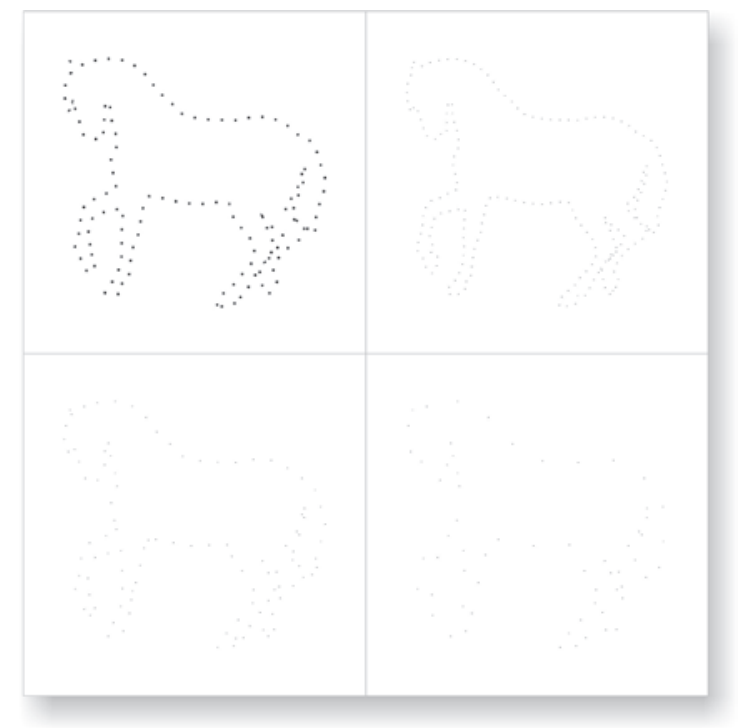

Figura 3 "Jogo do Adivinhe a Figura". 
Forma de Avaliação: deve ser anotado em formulário apropriado o nome da criança e a figura que originou a resposta correta.

Participantes e duração: o teste deve ser realizado individualmente, bastando 1 intérprete para a aplicação. Os alunos têm até 5 minutos para completar o jogo.

\section{Teste de percepção: Cor, Forma e Tamanho - "Jogo de Ligue os Pontos"}

Objetivo: utiliza-se a componente gestáltica "semelhança" para analisar qual a variável visual (forma, tamanho ou cor) leva aos melhores resultados para o agrupamento de feições em uma figura.

Justificativa: os resultados podem ajudar a definir qual a variável visual mais eficiente para aplicação em atividades de ordem educacional.

Preparação: as figuras foram elaboradas, de maneira que a ligação de seus pontos semelhantes (que poderia ser por forma, tamanho ou cores diferentes) formasse uma figura por completo e esta seria uma maçã, um vaso ou uma borboleta.

Procedimento: o intérprete deve fornecer ao aluno um conjunto de 3 figuras: uma figura contendo o jogo do ligue os pontos utilizando-se de cores diferentes para cada elemento da figura; outra figura contendo o jogo do ligue os pontos utilizando-se de tamanhos diferentes para cada elemento da figura; e por fim outra figura contendo o jogo utilizando-se de formas diferentes para cada elemento da figura. Quando as figuras estiverem prontas, deve o aluno dizer qual a figura que surgiu da ligação (Figura 4).

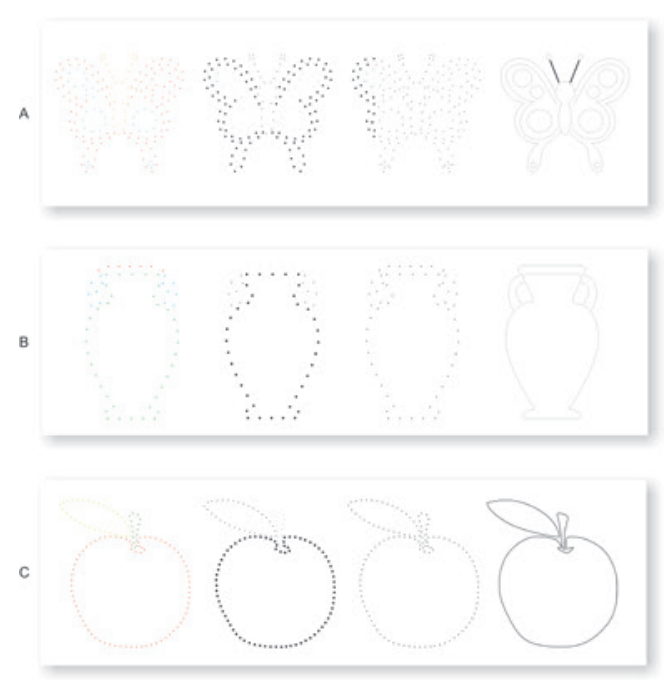

Figura 4 "Jogo de ligue os pontos" 
Forma de Avaliação: o intérprete deve anotar em um formulário o nome da criança, o tempo usado para a tarefa ser completada, bem como se a mesma foi terminada no prazo estabelecido e observações.

Participantes e duração: No mínimo 2. Tempo máximo para completar as 3 figuras é de 1 minuto. Deve existir 1 intérprete e 1 ajudante para cada 2 alunos.

\section{Teste de preferências subjetivas: variável cor}

Objetivo: avaliar preferência subjetiva de cor entre os entrevistados. Procura-se saber se existe um padrão que indique uma preferência subjetiva de cores e como ela pode ser correlacionada com as características da amostra.

Justificativa: as eventuais preferências podem ser utilizadas para embasar a criação de materiais visuais.

Procedimento: ao final da atividade, haverá um conjunto de 6 bexigas, de cores diferentes (representadas artisticamente na Figura 5), oferecidas como brinde pela participação. Cada criança deverá escolher uma bexiga para si.
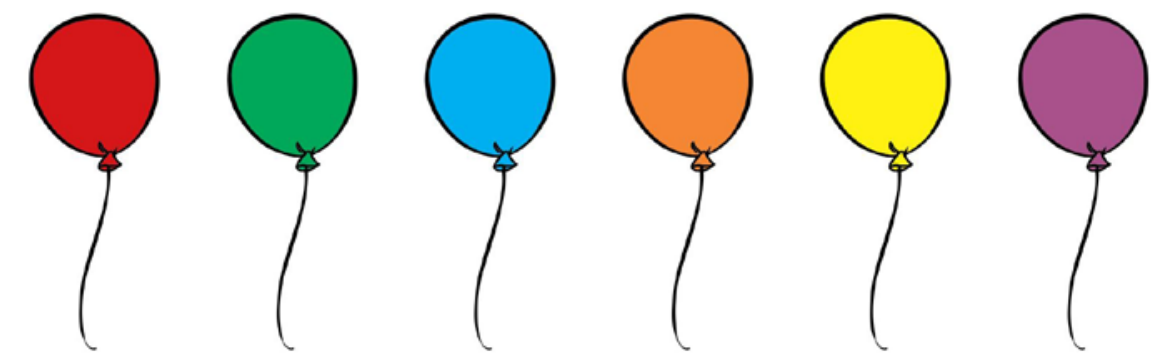

Figura 5 Sequência de cores de bexiga oferecidas às crianças.

Forma de Avaliação: deve ser anotado em um formulário o nome da criança, bem como a cor de bexiga escolhida por este.

\section{Estudo de caso}

É importante notar que a metodologia proposta aqui pretende gerar, por meio de análise estatística, resultados quantitativos acerca do público em questão. Mas que para a validação dos testes foi realizado um estudo de caso, cuja verificação qualitativa procurou levantar hipóteses preliminares a serem comprovadas pela replicação da metodologia com uma amostra futuramente fidedigna. 
Para o estudo de caso, a investigação adotou como população 15 crianças surdas, com idades entre 6 e 14 anos, com grau de escolaridade que varia do $1^{\mathrm{O}}$ ao $5^{\mathrm{O}}$ ano do ensino básico e que se utilizam da Libras como forma de comunicação. Todas as crianças são alunas de uma Escola Municipal de Educação de Surdos, localizada na Região Metropolitana de Curitiba.

Os testes foram realizados na escola, conforme as especificações previstas. Para tanto, foram necessárias duas tardes (de 13h3omin às $17 \mathrm{~h}$ ) para que fossem concluídas as atividades com todas as crianças. Os intérpretes foram os próprios professores da escola, com conhecimento na Língua de sinais, enquanto que os pesquisadores tiveram o papel de ajudantes. Os materiais utilizados para os testes foram:

Mensuração de fluência e domínio de Libras - um saco de pano contendo diversos brinquedos e objetos, formulários impressos em sulfite A4 e caneta esferográfica.

Teste de percepção: Cor, Forma, Tamanho - "Jogo da Memória”- 4 impressões em A3, cada uma correspondente a uma configuração proposta para o jogo. Dois jogos da memória impressos em triplex 300 , sendo que cada carta-figura tinha o tamanho de $5 \times 5 \mathrm{~cm}$ (total de 24 cartas-figuras por jogo), formulários impressos em sulfite $\mathrm{A} 4 \mathrm{e}$ caneta esferográfica.

Teste de percepção da variável cor: "Jogo dos 7 Erros"- 30 folhas em sulfite A5 (sendo 15 para o jogo dos 7 erros colorido e 15 para o $\mathrm{PB}$ ), lápis grafite, formulários impressos em sulfite $\mathrm{A}_{4} \mathrm{e}$ caneta esferográfica.

Teste de percepção: Cor, Forma e Tamanho - "Jogo de Ligue os Pontos"45 folhas em sulfite A5 (sendo que cada criança deveria completar 3 figuras: uma borboleta, um vaso e uma maçã), lápis grafite, formulários impressos em sulfite A4 e caneta esferográfica.

Percepção de completude: "Jogo do Adivinhe a Figura"- 4 folhas em sulfite A4 impressas (cada uma contendo uma figura de dificuldade diferente), formulários impressos em sulfite A4 e caneta esferográfica.

Teste de preferências subjetivas: variável cor- bexigas em diversas cores (vermelha, verde, azul, laranja, amarela e roxa), formulários impressos em sulfite A4 e caneta esferográfica.

\subsection{Resultados e discussões}

Embora se entenda que a amostra coletada não é suficientemente representativa para que se tenham respostas conclusivas acerca dos 
testes, os resultados obtidos sugerem algumas hipóteses e detalhes a serem pensados em testes futuros.

Verificou-se também que o caráter lúdico dos experimentos foi adequadamente aplicado. Pois, tornou a atividade prazerosa para as crianças que além de estarem à vontade no ambiente escolar, com os testes explicados em LS pelos seus professores, fizeram da atividade um momento de descontração e interação com os seus colegas. A seguir, são apresentados os resultados mais relevantes de acordo com cada teste.

\subsubsection{Mensuração de fluência e domínio de Libras}

As notas dadas (Figura 6) variam entre 1 e 4 ( 1 - nenhum domínio 2 - pouco domínio 3 -domínio básico 4 -domínio e fluência) e foram dadas por 5 avaliadores fluentes na LS em questão.

\begin{tabular}{|c|c|c|c|}
\hline & Idade & Série & Média \\
\hline Maria A & 12 & $5^{\circ}$ & 3,32 \\
\hline Maria B & 12 & $5^{\circ}$ & 3,52 \\
\hline João A & 14 & $5^{\circ}$ & 2,72 \\
\hline Maria C & 07 & $2^{\circ}$ & 1,75 \\
\hline João B & 07 & $2^{\circ}$ & 3,05 \\
\hline João C & 09 & $4^{\circ}$ & 3,36 \\
\hline João D & 10 & $2^{\circ}$ & 2,56 \\
\hline João E & 11 & $4^{\circ}$ & 2,24 \\
\hline João F & 10 & $4^{\circ}$ & 2,92 \\
\hline João G & 07 & $2^{\circ}$ & 3,24 \\
\hline Maria D & 06 & $1^{\circ}$ & 2,92 \\
\hline Maria E & 13 & $3^{\circ}$ & 2,28 \\
\hline Maria F & 11 & $4^{\circ}$ & 2,60 \\
\hline Maria G & 09 & $2^{\circ}$ & 3,20 \\
\hline Maria H & 10 & $2^{\circ}$ & 2,88 \\
\hline & & & \\
\hline
\end{tabular}

Figura 6 Notas para a mensuração em Libras. 
Aparentemente, o resultado do domínio de Libras está correlacionado ao tempo de exposição à língua. O levantamento de um histórico de cada criança participante junto à escola revela que, em geral, os melhores resultados coincidem com crianças que foram inseridas na língua mais precocemente.

Cita-se o caso de "Maria D", 6 anos, que está na escola desde o maternal, e apresentou um desempenho superior ao dos estudantes "Maria F" e "João A", mais velhos, porém com um ano na escola apenas. Outro exemplo é o da aluna "Maria C", que ingressou na escola no ano corrente, não tendo a mesma cursado o primeiro ano em uma escola bilíngue. Mesmo assim foi aprovada para a $2^{\underline{0}}$ série com conhecimento nulo de Libras.

De forma geral, os resultados para este teste não parecem estar diretamente correlacionados com o desempenho obtido nos demais testes, o que nos leva a sugerir que a relação entre o domínio de Libras e as habilidades visuais para resolução de tarefas com base em elementos visuais não é significativa.

\subsubsection{Teste de percepção: Cor, Forma, Tamanho - "Jogo da Memória"}

O resultado obtido para esta tarefa demonstra que os elementos com variação em cor e tamanho foram mais escolhidos pelas crianças ( $42,86 \%$ para cor e $35,71 \%$ para tamanho e $21,43 \%$ para forma). Obviamente que, em uma análise completa, seria necessário a aplicação de um teste de correlação estatística, para saber, se a diferença realmente pode ser considerada como significativa. Porém, tal resultado pode ser um indicativo de que a variação em forma não parece ser efetiva no que diz respeito à tarefa de chamar a atenção das crianças visualmente. O que poderia indicar que a utilização de elementos visuais baseados em cor e tamanho podem ser mais indicados para, por exemplo, apreender a atenção inicial da criança.

A cor foi a variável escolhida que provocou o maior índice de primeira tentativa bem-sucedida para a formação de um par (50\% para cor, $16,67 \%$ para tamanho e 33,33\% para forma na configuração 1 e $50 \%$ para cor, $37,5 \%$ para tamanho e $12,5 \%$ para forma na configuração 2).

Mesmo não sendo uma variável proposta a ser avaliada de início, a variável localização também parece ter influência no processo, uma vez que de acordo com a configuração, os resultados tiveram uma variação supostamente significativa ( $50 \%$ de acerto na primeira tentativa para a configuração 1 e $37,5 \%$ de acerto na primeira tentativa para a configuração 2). Porém, para o caso da análise aqui realizada, problemas com os aplicadores e alunos causaram a ausência de anotações relativas à posição de cada carta-figura aberta. Para uma análise completa, deve-se ter em mente que este fator é preponderante para a correta mensuração da importância da variável localização neste tipo de atividade. 


\subsubsection{Teste de percepção da variável cor: "Jogo dos 7 Erros"}

Comparando-se os resultados entre o jogo dos 7 erros colorido e o mesmo construído em preto e branco, pode-se constatar que o desempenho é melhor para o segundo caso, uma vez que o tempo necessário para que se encontre os 7 erros é menor. Assim, é possível sugerir, a partir dos resultados, que a variável cor não contribui positivamente em situações complexas que exijam concentração para a resolução de um problema, o que deve ser testado em situações de aprendizado.

Nota-se também, que o desempenho no jogo colorido caiu a partir do quinto erro, o que ocorreu nos jogos em pb apenas a partir do sexto erro - lembrando que o mesmo só foi possível até o limite máximo de contagem de tempo, quando o mesmo parou de ser mensurado. $\mathrm{O}$ fato de haver esta queda indica que a criança não parece, a partir de certo momento da atividade, estar motivada com o material, o que causa desistência. Esta motivação acabou antes para o caso do jogo colorido.

Por fim, observou-se que o percentual de crianças que não conseguiu completar a tarefa é bastante elevado, sugerindo uma melhor investigação correlacionando a desistência da atividade aos resultados relativos ao atraso na aquisição da Libras.

\subsubsection{Percepção de completude : "Jogo do adivinhe a figura"}

Nesta atividade, o resultado permite sugerir que a maioria dos entrevistados consegue identificar a figura por meio da visualização das imagens com maior complexidade (40\%).

Tal fato sugere de que a pregnância da forma é entendida satisfatoriamente. Isso pode ser explorado no design de atividades que incluam o uso da variável forma, podendo este ser um indicativo que estas crianças conseguem suportar cognitivamente a identificação de formas com maior grau de complexidade. E nos resultados deste teste, a identificação da imagem mais complexa foi independente da mensuração de Libras dada à criança participante. O que sugere habilidades visuais inerentes ao público surdo e não associadas ao aprendizado de uma LS.

\subsubsection{Teste de percepção: Cor, Forma e Tamanho - "Jogo de Ligue os Pontos"}

Acerca da eficácia (100\% maçã, 55,56\% vaso e 50\% borboleta), esta parece estar mais relacionada com a forma da figura em geral (o todo) do que com as variáveis usadas em cada ponto a ser ligado, o que pode ser notado para os resultados obtidos com diferentes variáveis visuais usadas na construção das três figuras. Considera-se isto como relevante, pois consiste em uma demonstração de que há uma 
hierarquia de importância, onde o todo está no topo, em detrimento das partes.

No que diz respeito à eficiência (tempo), pôde-se concluir que há um resultado semelhante à eficácia da atividade, com uma maior dificuldade para a figura de características mais complexas (maior número de pontos e maior complexidade de forma) e uma diferença maior em relação à comparação entre os mesmos itens, para a eficácia (124,3s maçã, 155,33 s vaso e 274 s borboleta). Os resultados obtidos para cada uma das variáveis visuais podem sugerir que o uso de forma e contraforma tornam a atividade mais difícil para as crianças.

\subsubsection{Teste de preferências subjetivas: variável cor}

Os resultados (30,77\% vermelho, 30,77\% roxo, 15,38 azul, $15,38 \%$ amarelo e $7,70 \%$ verde) demonstram a subjetividade deste tipo de verificação.

\section{Conclusão e trabalhos futuros}

Este trabalho caracteriza-se como o passo inicial na direção de uma metodologia de testes a propor subsídios para embasar escolhas de comunicação visual específicas ao ensino-aprendizagem de crianças surdas.

Um estudo de caso validou a metodologia e indicou que a abordagem etnográfica, bem como o caráter lúdico (jogos), teve um retorno positivo por parte das crianças participantes. Os resultados obtidos com o estudo de caso foram qualitativos e geraram algumas hipóteses. Dentre elas, destaca-se: o fato de uma melhor nota à mensuração de Libras estar atrelada ao tempo de exposição da criança a esta língua e que isto é decorrente do tempo em que a criança frequenta um ambiente escolar bilíngue. De acordo ainda com os resultados, a cor é a variável gráfica que mais chama a atenção à primeira vista, seguida do tamanho. Em situações mais complexas de análise de um material gráfico, a cor parece tornar mais difícil a realização da tarefa (como encontrar erros). As crianças surdas apresentam boa pregnância da forma e a identificação de figuras complexas por este público parece ser independente do domínio de uma LS. Porém, o uso de contraforma parece dificultar para tal público o entendimento da completude de uma figura.

Vale ressaltar que, a validação dos resultados e das hipóteses (análise quantitativa) depende da aplicação dos testes junto a uma amostra estatisticamente representativa de participantes surdos. Porém, cabe dizer, que o público infantil surdo merece maior atenção para suas especificidades visuais e uma melhor compreensão de como percebe a informação ao seu redor, especialmente no ambiente educacional. Este tipo de abordagem deve ter como objetivo o 
desenvolvimento de materiais eficientes e específicos para este público e para tal, deve-se continuar com a aplicação de testes que permitam uma melhor apropriação do universo visual destas crianças.

\section{Referências}

BELLUGi, U.; POIZNER, H.; KLIMA, E.S. (1989). Language, modality and the brain. Trends in. Neurosciences, 10, p. 380-388.

BERTIN, J. (1983). Semiology of Graphics. University of Wisconsin Press, Madison. CAPOVilla, F.; CAPOVilla; A. G. S.; Viggiano, K. (2005). Processos logográficos, alfabéticos e lexicais na leitura silenciosa por surdos e ouvintes. Estud. psicol. Natal, 10, 1, p. 15-23.

EMMOREY, K.; KOSSLYN, S. M.; BELLUGI, U. (1993). Visual imagery and visual spatial language - enhanced imagery abilities in deaf and hearing asl signers. Cognition. n.46. Elsevier Science Publishers. p.139-181.

FERnANDes, S. F. (2006). Práticas de letramentos na educação bilíngue para surdos. SEED, Curitiba.

Gomes FIlHo, JoÃo. (2004). Gestalt do Objeto: Sistema de Leitura Visual da Forma. São Paulo: Editora Escrituras. 6ª ed.

MiRzoeff, N. (1999). An introduction to visual culture. London: Routledge. mCCullough, s.; EMmorey, K. (1997). Face Processing by deaf ASL Signers: Evidence for Expertise in Distinguishing Local Features. Journal of Deaf Studies and Deaf Education 2:4. Oxford University Press. p. 212-222.

PARASnis, I., SAmar, V. J., Bettger, J. G., SATHe, K. (1996). Does Deafness Lead to Enhancement of Visual Spatial Cognition in Children? Negative Evidence from Deaf Nonsigners. In Journal of Deaf Studies and Deaf Education 1:2. Spring. Oxford University Press, p. 145-152.

QUADROS, R. M. (2006). Ideias para ensinar português para alunos surdos. Brasília: MEC, SEESP.

SIPLE, P.; HATFIELD; N., CACCAMISE, F. (1978). The role of visual perceptual abilities in the acquisition and comprehension of sign language. American Annals of the Deaf. 123,7 , p. 852-856.

sofiato, C. G. (2005). O desafio da representação pictórica da língua de sinais brasileira. Dissertação (mestrado em Artes Visuais), Instituto de Artes, Universidade Federal de Campinas.

StUmpF, M. (2005). Aprendizagem de escrita de língua de sinais pelo sistema signwriting: línguas de sinais no papel e no computador. Porto Alegre: Ufrgs, Tese (Doutorado em Informática na Educação), Pós-Graduação em Informática na Educação, Universidade Federal do Rio Grande do Sul. TODMAN, J., SEEDHOUSE, E. (1994). Visual-action code processing by deaf and hearing children. Language and Cognitive Processes, 9, p. 129-141.

VIGOTSKY, L.s. (1974). Mind in society: the development of higher psychological processes. Harvard University Press, Cambridge. 


\section{Sobre os autores}

\section{Juliana Bueno}

<juliana@inf.ufpr.br>

Possui graduação em Design Gráfico pela Universidade Federal do Paraná/UFPR (2006), é mestre (2009) e doutoranda do Programa de Pós-Graduação em Informática, também, pela UFPR (área de IHC). Atua principalmente nas seguintes áreas: design de interfaces, inclusão digital, acessibilidade, design educacional e letramento bilíngue de crianças surdas.

\section{André Luiz Alencar de Mendonça}

<andremalms@hotmail.com>

Possui graduação em Engenharia Florestal pelo Instituto de Tecnologia da Amazônia (2003), Especialização em Geotecnologias, Mestrado e Doutorado em Ciências Geodésicas pela Universidade Federal do Paraná. Atua principalmente nas seguintes áreas: investigação e desenvolvimento mapas interativos para web, cartografia e Sistemas de Informação Geográfica, softwares design e acessibilidade em interfaces e bancos de dados geográficos.

\section{Laura Sánchez García}

<laura@inf.ufpr.br>

Possui Graduação em Licenciatura Plena em Matemática pela Universidade Federal do Paraná (1981), Mestrado em Informática (1990) e Doutorado em Ciência da Computação (1995) pela PUCRIO. É professora associada do Departamento de Informática da UFPR. Atualmente desenvolve trabalhos nos seguintes temas: ambientes colaborativos inclusivos, ambientes acessíveis, ambientes de apoio ao ensino e à aprendizagem via web, ferramentas de apoio à representação e ao processamento de conhecimento linguístico.

Artigo recebido em 04 nov. 2013, aprovado em 12 dez. 2013. 